\title{
Analysis on the Business Administration Problems in Market Supervision and the Countermeasures
}

\author{
Rui Wang \\ Xi'an International University, \\ Xi'an 710077, Shaanxi
}

\begin{abstract}
Industrial and commercial administrative departments shoulder an important responsibility for the comprehensive market supervision, and usually directly contact with the market's main body. These departments are gradually strengthening the administrative law enforcement and laying more emphasis on the reasonable layout of the key field supervisions when constantly improving and changing the self-management mechanism. Hopefully, the stability of the market situation will always be continued under the present situation of increasingly market subject quantity since the reform of food and drug safety and commercial systems, so as to secure the capability to control the market risks. It is necessary to admit that the fierce market competitive situation brought by the social and economic transformation promotes the market subjects as well as operational models to be diversified. In these circumstances, many market subjects become acute, and the contradictions such as product safety problem, unlicensed problem, and fake problem produced in the economic and business operation models are increasingly obvious, thus making the difficulty of the industrial and commercial administrative departments enlarged in the market supervision. In this paper, the main problems encountered by the grass-roots industrial and commercial administrative departments in the market supervision and the causes are analyzed comprehensively, and also the related countermeasures for these departments to improve the market supervision are discussed under the background of the comprehensive reform of the market economy.
\end{abstract}

Keywords- Industrial and Commercial Administrative Departments; Market Supervision; Market Subjects; Administrative Law Enforcement; Administrative Strategies

\section{Introduction}

Industrial and commercial administrative departments are comprehensive market supervisor departments directly managed by the government. These departments involve a very wide range of businesses, and therefore, the market supervision tasks are onerous. In recent years, a series of new policies have been issued under the situation of the market economic reform, and industrial and commercial administrative departments encounter various difficulties and obstacles in the face of new situation and problems. Therefore, in the changing social environment, how to quickly adapt to the new situation, integrate various problems and also provide solutions is a question necessary to industrial and commercial administrative departments to think about in market supervision.

2. The market supervision by industrial and commercial administrative departments

\subsection{The main contents of the market supervision}

The important functions of the national economic administrative regulation are performed by industrial and commercial administrative departments. The main contents of the market supervision include the management and registration of market subjects, market trading and market competition order, the legitimate rights and interests of consumers, trademark protection and advertising supervision, and illegal marketing and MLM supervision. 


\subsubsection{The registration of market subjects}

The registration of market subjects is implemented by the competent authorities completely according to the social laws or related rules. It includes the establishment, change, termination of the applications submitted by the market subjects, and also provides examining and approval requirements. Then, the business qualification and position of the market subjects are confirmed.

\subsubsection{The maintenance of market transaction and} competition order

The departments are responsible for establishing and maintaining a fair market transaction and competition order, giving full play to the market mechanism function, correcting the economic failures in the market, and promoting the market subjects to take part in transactions in a free, fair, equal, and honesty environment.

2.1.3 Protecting the legitimate rights and interests of consumers

All kinds of marketing behaviors inconsistent with the legitimate rights and interests of consumers are attacked and restricted. This is good maintenance for the market consumption environment, but also the best protection for the legitimate rights and interests of consumers.

2.1.4 Trademark protection and advertising regulation

Trademark protection and advertising supervision mean that the behaviors violating trademark, advertising management, and management order are examined and corrected. That is to say, false and illegal advertisements are hit to spread, and simultaneously the healthy and orderly development of the national advertising industry is promoted.

\subsubsection{Illegal marketing and MLM supervision} In Regulations on Forbidding MLM, the people's governments at all levels, industrial and commercial administrative departments, police offices and other law enforcement departments have clearly showed that illegal marketing and MLM behaviors are necessarily strictly examined and attacked, so as to secure the steady and harmonious state in the market supervision order.

\subsection{The market supervision characteristics of industrial and commercial administrative departments}

\subsubsection{Directness}

In China, the vast majorities of the market subjects are registered and then directly supervised by the industrial and commercial administrative departments. Under the effect of the market supervision in China, the high-level industrial and commercial administrative departments have decentralized the supervision responsibilities to the local departments, so that the grass-roots industrial and commercial administrative departments have been the supervisors to directly supervise the market subjects. Therefore, the market supervision is direct.

\subsubsection{Enforceability}

Enforceability is inevitable. On the one hand, the full implementation of all laws and regulations is realized through the grass-roots industrial and commercial administrative departments. On the other hand, the economic behavior of the market subjects has law to abide by.

\subsubsection{Comprehensiveness}

At present, the number of the legal provisions involved in the market supervision by the industrial and commercial administrative departments of China is more than 230, including various administrative rules and regulations and regulatory behaviors. Through these rules and laws, the industrial and commercial administrative departments have cooperated with many governmental departments to implement the joint supervision. But this also allows them to own the comprehensive scope of law enforcement and power in the government regulators [1]. 


\section{Problems in the market supervision by industrial and commercial administrative departments}

Under the condition of the deliberate reform of the domestic environment and market supervision system in the transformation period of market economy, the market supervision encounters many problems because of the weak adaptability of the industrial and commercial administrative departments or the vulnerabilities of new polices, so that the smooth development of the work of the industrial and commercial administrative departments and also the stable development of the market supervision system are hindered.

\subsection{The non-registration of market subjects}

From the current market situation, the non-registration of market subjects is mainly reflected from five aspects. First, required certificates and licenses are absent. For example, many catering service subjects do not acquire a food and beverage service license. Second, direct license is absent. For example, some companies in the electronic industry do not apply for an official business license. Third, certificates are available, but licenses are absent. This type of companies has acquired a business permit, but opens their business without acquiring a business license. Fourth, permit and license are invalid. Some companies do not apply for the continuation of their business permit and license deliberately or negatively after the permit and license are invalid, but this action is not responded by the industrial and commercial administrative departments in a timely manner. According to the rules in Measures on Cracking down the Business Operation without Permit and License, a company with an invalid license will be withdrawn and closed down if it is still in the market economy activities; a company without certificates but with license will be legally punished if it does some economic activities unrelated to the qualification and disturbs the normal market economic order.

\subsection{Problems in the market supervision and administration law enforcement}

In the market supervision and administration law enforcement, the problems are mainly from the management of the law enforcement case sources (i.e. the key risk), specifically reflected in the following four aspects.

First, the problems are from the departments accepting and hearing a case. Seen from the current situation, a unified registration system has not been formed by China's industrial and commercial administrative departments in accepting and hearing a case, so that the acceptance problems and errors are extremely easily caused in many aspects.

Second, the problems are from the absence of a coordination department in the industrial and commercial administrative departments. There are many branches of industrial and commercial administrative departments to bear the market supervision, and thus, cross-regulation behaviors often emerge, making it easier to result in the waste of administrative resources. The rework status in the cross-regulation behaviors also leads to the internal disorder of the industrial and commercial administrative departments; there are no appropriate and reasonable coordination mechanism and corresponding coordination departments, making the market supervision into confusion.

Third, the quality of accepting and hearing a case cannot be guaranteed. In view of many cases to be processed, many domestic industrial and commercial administrative departments show an indifferent attitude toward the problems reflected in the cases more or less, and do not seriously examine and review the cases and carefully collect the related evidences about the cases. As a result, great difficulties are caused to the case processing.

Finally, the problems are from the lack of supervision mechanism. The supervision mechanism in China mainly comes from the upper level to the lower level, and it is an audit guidance system authorized by the legal 
institutions, so it is the category of the supervision [2].

\section{Countermeasures in the process of improving the market supervision by industrial and commercial administrative departments}

In view of the practical problems in the current market supervision implemented by industrial and commercial administrative departments, the targeted improvement countermeasures are raised in the following, expecting to stably ease the contradiction between market subjects, the contradiction between market subjects and industrial and commercial administrative departments, and the contradiction between the masses, balance the interests and promote the harmonious and stable development of the market economy.

\subsection{Solution to the non-registration of market subjects}

The legal construction of market subjects is an important basis for the development of the modern market system. On the basis, the market supervision implemented by industrial and commercial administrative departments is especially important. In this process, the purpose of market regulation lies in the standardization of the market subject registration and management behaviors and the construction of a good market environment.

\subsection{Scientific supervision}

Industrial and commercial administrative departments of China should actively promote the reform of "license before certificate" among the market subjects and also construct the scientific administrative examination and approval operating mechanism between government departments, for the purpose of implementing information cue, manpower, feedback and statistical processing between different departments, and integrate "three certificates"-business license, tax registration certificate and organization code certificate are scientifically managed.

\subsection{Processing by batches and classification}

The basic market supervision policy is necessarily implemented by the industrial and commercial administrative departments. For the business operation without a business license, official documents are necessarily distributed to the market subjects timely; the reasonable transfer of departmental responsivities is quickly implemented on the premise of no problems; the market subjects difficult to register are processed by batches stably. At the same time, great manpower and material resources are invested, to improve the guarantee for the market supervision.

\subsection{Strengthening the administrative law enforcement work in the market supervision}

To strengthen the administrative law enforcement work in the market supervision, the following two points are necessarily followed.

First, the unified management of the case source clues is strengthened; industrial and commercial administrative departments should establish the corresponding rules and regulations strictly according to the case source clues management flow. The case source clues management flow is divided into five parts: receiving, acceptance, distribution, suggestion feedback, and market subject supervision. Meanwhile, the standards and relevant procedures are necessarily followed strictly in accordance with the flow.

Second, innovation and breakthrough for the way of law enforcement and supervision are realized; intervention is implemented in the whole process. In this paper, it is thought that in the supervision and intervention of industrial and commercial administrative departments, three aspects are necessarily followed. First, it is necessary to implement special and compulsory administrative measures for cases. Second, it is necessary to carry out a normalized development 
for law enforcement and supervision. Third, it is necessary to regularly plan reasonable compulsory administrative behaviors [3].

\section{Conclusion}

In this paper, the difficulties in the market supervision implemented by industrial and commercial administrative departments during the transformation and reform of the market economy are briefly introduced, and also the related countermeasures are analyzed in a targeted way. For example, the non-registration and market supervision law enforcement problems are solved. Thus, the advancement and innovation of the market supervision and law enforcement by industrial and commercial administrative departments are obvious to all.

\section{References}

[1] Ying Cao. Study on the Problems in the Process of Industrial and Commercial Administrative Departments to Strengthen the Market Supervision [D]. Zhengzhou University, 2004.10-14.

[2] Hong Lei. Analysis on the Functions of Industrial and Commercial Management Departments in Food Safety RegulationJiangxi Province Is Taken for Example [D]. Nanchang University, 2013.15-21.

[3] Nannan Meng. Study on the Problems in the Process of the grass-roots Industrial and Commercial Administrative Departments to Strengthen the Market Supervision [D]. Shandong University, 2012.26-31. 